УДК 591.69-82:598.23:598.24:598.244(571.54)

DOI 10.18101/2542-0623-2020-3/4-34-43

\title{
ЭКОЛОГО-ФАУНИСТИЧЕСКИЙ АНАЛИЗ ГЕЛЬМИНТОВ ВОДНО-БОЛОТНЫХ ПТИЦ БАЙКАЛЬСКОЙ СИБИРИ: 4. ГАГАРОВЫЕ, БАКЛАНОВЫЕ, ЦАПЛЕВЫЕ, ПОГАНКОВЫЕ, ПАСТУШКОВЫЕ
}

\section{Ц. 3. Доржиев, Е. Н. Бадмаева, Ж. Н. Дугаров}

\section{(C) Доржиев Цыдыпжап Заятуевич}

доктор биологических наук, профессор, Бурятский государственный университет имени Доржи Банзарова Россия, 670000, г. Улан-Удэ, ул. Смолина, 24а Институт общей и экспериментальной биологии СО РАН Россия, 670047, г. Улан-Удэ, ул. Сахьяновой, 6 tsydypdor@mail.ru

\section{(C) Бадмаева Евгения Николаевна} кандидат биологических наук, Бурятский государственный университет имени Доржи Банзарова Россия, 670000, г. Улан-Удэ, ул. Смолина, 24а calidris03@gmail.com

\section{(C) Дугаров Жаргал Нимаевич}

кандидат биологических наук, старший научный сотрудник, Институт общей и экспериментальной биологии СО РАН Россия, 670047, г. Улан-Удэ, ул. Сахьяновой, 6 zhar-dug@biol.bscnet.ru

Аннотация. Приведен видовой состав гельминтов 8 видов птиц из семейств гагаровые (краснозобый и чернозобый гагары), баклановые (большой баклан), цаплевые (серая цапля), поганковые (чомга, черношейная и красношейная поганки) и пастушковые (лысуха) Байкальской Сибири. Общий объем материала небольшой, всего вскрыто 94 птицы, из них основная доля принадлежит чомге и лысухе, остальные виды представлены 2-7 особями. У чомги выявлено 46 видов гельминтов: цестод 13 видов, трематод - 25, нематод - 6, скребней - 2. У лысухи обнаружено 11 видов паразитов: цестод - 3, трематод - 3, нематод - 1 , скребней - 4 .

Основную долю паразитов составляют цестоды и трематоды, нематоды уступают им. Участие скребней в населении гельминтов исследованных групп птиц низкое. Лишь у лысухи доля скребней по отношению к другим классам гельминтов была несколько выше. Установлено, что часть видов гельминтов специфична для разных групп птиц. Многие виды водно-болотных птиц в паразитологическом плане остаются слабо или вообще не изученными. В первую очередь следует обратить внимание на многочисленные и обычные виды птиц.

Ключевые слова: гельминты; паразиты птиц; гагары; бакланы; поганки; цапли; лысуха; озеро Байкал; Байкальская Сибирь. 
Ц. 3. Доржиев, Е. Н. Бадмаева, Ж. Н. Дугаров. Эколого-фаунистический анализ гельминтов водноболотных птиц Байкальской Сибири: 4. Гагаровые, баклановые, цаплевые, поганковые, пастушковые

\section{Для цитирования}

Доржиев Ц. 3., Бадмаева Е. Н., Дугаров Ж. Н. Эколого-фаунистический анализ гельминтов водно-болотных птиц Байкальской Сибири: 4. Гагаровые, баклановые, цаплевые, поганковые, пастушковые // Природа Внутренней Азии. Nature of Inner Asia. 2020. № 3/4(16). C. 34-43. DOI: 10.18101/2542-0623-2020-3/4-34-43

\section{Введение}

Предыдущие статьи из данной серии были посвящены гельминтам утиных, ржанковых и чайковых птиц [Доржиев, Бадмаева, Дугаров, 2019, а, б, 2020]. В нашем распоряжении оказались некоторые сведения еще по пяти семействам из пяти отрядов водно-болотных птиц Байкальской Сибири: семейства гагаровые Gaviidae, баклановые Phalacrocoracidae, цаплевые Ardeidae, поганковые Podicipedidae, пастушковые Rallidae.

Видовое разнообразие гельминтов и объем набранного материала по этим семействам изучены слабо. По гельминтам этих групп птиц в регионе известно немного [Ошмарин, 1947, 1965; Скрябин, 1947; Быховская-Павловская, 1962; Некрасов, Жатканбаева, 1982; Некрасов, Санжиева, Егоров, 1982; Подковыров и др., 1988; Некрасов, 1989, 2000, 2003; Тимошенко, 1990; Подковыров, Некрасов, Пыжьянов, 1991; Подковыров и др., 1991; Некрасов, Пронин, Дугаров, 2001].

Цель работы - представить имеющиеся данные по гельминтам этих пяти семейств водно-болотных птиц Байкальской Сибири.

\section{Материал и методика}

Основой написания статьи послужили литературные сведения и неопубликованные данные А. В. Некрасова, собранные им и его коллегами в 1971-2003 гг. в разных частях оз. Байкал и на оз. Гусиное. Всего исследовано 8 видов из 5 семейств, относящихся 5 отрядам (табл. 1). Общий объем материала небольшой, всего вскрыто 94 птиц, из них основная доля принадлежит чомге и лысухе, остальные виды представлены 2-7 особями. Птицы изучены методом полного и неполного гельминтологического вскрытия по К. И. Скрябину. Таксономическая принадлежность цестод определена по Л. П. Спасской (1966), нематод и трематод — по А. А. Шевцову, Л. Н. Заскинду (1960).

\section{Результаты и обсуждение}

Семейство гагаровые в Байкальской Сибири представлено тремя видами. Краснозобая и чернозобая гагары относятся к редким перелетным гнездящимся видам, белоклювая гагара известна как единично залетная птица. Гагары питаются рыбами и водными беспозвоночными.

У пяти вскрытых краснозобых гагар выявлено 11 видов гельминтов: цестод 8 , трематод - 1 и нематод - 2 (табл. 2). Интенсивность заражения составляла $100 \%$.

У двух исследованных чернозобых гагар обнаружено пять видов паразитов: цестод - 3 и нематод - 2 . Большинство видов паразитов гагар имели хозяев и среди других групп водно-болотных птиц. Цестода Dubininilepis rostellat обнаружена в регионе только в краснозобой гагаре [Некрасов, 2000]. Многие виды гельминтов гагар, известных в других регионах, пока не обнаружено [Смогоржевская, 1976; Яковлева, Лебедева, Иешко, 2013, 2015]. 
Количество исследованных видов некоторых семейств водно-болотных птиц и зараженность их гельминтами в Байкальской Сибири

\begin{tabular}{|c|c|c|c|c|c|c|}
\hline \multirow[b]{2}{*}{ Названия птиц } & \multirow[b]{2}{*}{$\begin{array}{l}\text { Изучено/ } \\
\text { заражено } \\
\text { особей }\end{array}$} & \multicolumn{5}{|c|}{ Число видов гельминтов } \\
\hline & & $\begin{array}{l}\text { Цестоды } \\
\text { Cestoda }\end{array}$ & $\begin{array}{l}\text { Трематоды } \\
\text { Trematoda }\end{array}$ & $\begin{array}{l}\text { Нематоды } \\
\text { Nematoda }\end{array}$ & $\begin{array}{c}\text { Скребни } \\
\text { Acantha- } \\
\text { cephala } \\
\end{array}$ & Всего \\
\hline \multicolumn{7}{|c|}{ Семейство Гагаровые Gaviidae } \\
\hline $\begin{array}{l}\text { Краснозобая гагара } \\
\text { Gavia stellata }\end{array}$ & $5 / 5$ & 8 & 1 & 2 & 0 & 11 \\
\hline $\begin{array}{l}\text { Чернозобая гагара } \\
\text { Gavia arctica }\end{array}$ & $2 / 2$ & 3 & 0 & 2 & & 5 \\
\hline \multicolumn{7}{|c|}{ Семейство Баклановые Phalacrocoracidae } \\
\hline $\begin{array}{l}\text { Большой баклан } \\
\text { Phalacrocorax carbo }\end{array}$ & $3 / 3$ & 3 & 1 & 2 & 0 & 6 \\
\hline \multicolumn{7}{|c|}{ Семейство Цаплевые Ardeidae } \\
\hline $\begin{array}{l}\text { Серая цапля } \\
\text { Ardea cinerea }\end{array}$ & $2 / 1$ & 1 & 4 & 1 & 0 & 6 \\
\hline \multicolumn{7}{|c|}{ Семейство Поганковые Podicipedidae } \\
\hline $\begin{array}{l}\text { Чомга } \\
\text { Podiceps cristatus }\end{array}$ & $44 / 32$ & 13 & 25 & 6 & 2 & 46 \\
\hline $\begin{array}{l}\text { Черношейная поганка } \\
\text { Podiceps nigricollis }\end{array}$ & $3 / 3$ & 3 & 4 & 2 & 0 & 9 \\
\hline $\begin{array}{l}\text { Красношейная } \\
\text { поганка } \\
\text { Podiceps auritus }\end{array}$ & $7 / 6$ & 4 & 4 & 5 & 0 & 13 \\
\hline \multicolumn{7}{|c|}{ Семейство Пастушковые Rallidae } \\
\hline Лысуха Fulica atra & $28 / 23$ & 3 & 3 & 1 & 4 & 11 \\
\hline
\end{tabular}

Гельминты семейство гагаровых в Байкальской Сибири

\begin{tabular}{|c|c|c|}
\hline Виды гельминтов & $\begin{array}{c}\text { Краснозобая } \\
\text { гагара } \\
\end{array}$ & Чернозобая гагара \\
\hline \multicolumn{3}{|c|}{ Цестоды } \\
\hline Diphyllobothrium dendriticum (Nitzsch, 1824) & + & + \\
\hline Diphyllobothrium ditremum (Creplin, 1825) & + & - \\
\hline Ligula intestinalis (Linnaeus, 1758) & + & + \\
\hline Ligula colymbi (Zeder, 1803) & + & - \\
\hline Schistocephalus solidus (Müller, 1776) & + & + \\
\hline Lateriporus clerci (Johnston, 1912) & + & - \\
\hline Tetrabothrius macrocephalus Rudolphi, 1819 & + & - \\
\hline Dubininolepis rostellata (Abildgaard, 1790) & + & \\
\hline \multicolumn{3}{|c|}{ Трематоды } \\
\hline Echinochasmus skrjabini (Oschmarin, 1947) & + & - \\
\hline \multicolumn{3}{|c|}{ Нематоды } \\
\hline Contracaecum spiculigerum (Rudolphi, 1809) & + & + \\
\hline Streptocara crassicauda (Creplin, 1829) & + & + \\
\hline
\end{tabular}


Ц. 3. Доржиев, Е. Н. Бадмаева, Ж. Н. Дугаров. Эколого-фаунистический анализ гельминтов водноболотных птиц Байкальской Сибири: 4. Гагаровые, баклановые, цаплевые, поганковые, пастушковые

Семейство баклановые в Байкальской Сибири представлено большим бакланом. У трех вскрытых птиц найдено 6 видов гельминтов. Отмечено цестод три вида - Ligula intestinalis, Ligula colymbi, Pseudanomotaenia micracantha [Krabbe, 1869]; трематод один вид — Echinoparyphium macrovitellatum Oschmarin, 1947; нематод два вида - Contracaecum spiculigerum, Paradilepis scolecina [Rudolphi, 1819]. Сосальщик Echinoparyphium macrovitellatum и круглый червь Paradilepis scolecina выявлен в регионе только у баклана [Некрасов, 2000]. Echinoparyphium macrovitellatum является специфическим гельминтом большого баклана [Скрябин, 1947; Быховская-Павловская, 1962]. Остальные виды обнаружены у некоторых других водно-болотных птиц. Вообще, судя по литературным данным из других регионов [Смогоржевская, 1976; Семенова, Калмыков, Иванов, 2009; Махмудова, 2013], гельминтофауна лысух очень богата.

В настоящее время большой баклан стал одним из самых многочисленных птиц Байкала и других крупных водоемов Прибайкалья и Забайкалья. В связи с этим он становится объектом специальных исследований экологов и паразитологов. Со временем, несомненно, расширится видовое разнообразие его гельминтов.

Семейство цаплевые в Байкальской Сибири насчитывает пять видов, из них четыре вида относятся к перелетным гнездящимся и один - залетным [Доржиев, 2011]. Самым обычным среди них является серая цапля. У двух вскрытых птиц серой цапли обнаружено шесть видов гельминтов: цестод один вид - Gryporhynchus pusillus Nordmann, 1832; трематод 4 вида - Clinostomum complanatum [Rudolphi, 1809]; Petasiger aeratus [Oschmarin, 1947]; Petasiger spasskyi [Oschmarin, 1947]; Apharyngostrigea cornu [Zeder, 1800]; нематод один вид — Desmidocercella numidica [Seurat, 1920].

Только у серой цапли из водно-болотных птиц региона обнаружены сосальщики Clinostomum complanatum, Petasiger spasskyi, круглый червь Desmidocercella numidica, a Petasiger aerates и Apharyngostrigea cornu выявлены кроме нее еще у чомги. Другие виды паразитов имели большой круг хозяев [Ошмарин, 1965; Некрасов, 2000].

Серая цапля, питающаяся различными водными и околоводными животными - рыбой, земноводными, беспозвоночными, имеет возможность заразиться многими видами гельминтов. У данной цапли с территории бывшего СССР известно более 30 видов гельминтов [Быховская-Павловская, 1962; Спасская, 1963, 1966; Семенова, Калмыков, Иванов, 2009].

Семейство поганковые. Из пяти видов поганок Байкальской Сибири исследовано три, из них чомга была представлена достаточно большим объемом материала - 44 особи, из них 32 (72,7\%) были заражены. У поганок, особенно у чомги, выявлено большое число гельминтов (табл. 3). Чомга была заражена 46 видами гельминтов: цестод обнаружено 13 видов, трематод - 25, нематод - 6, скребней - 2. У трех исследованных особей черношейной поганки найдено всего 9 видов паразитов: цестод - 3, трематод - 4, нематод - 2. Красношейных поганок было вскрыто 7 особей, из них зараженными гельминтами оказались 6. Установлено у них 13 видов гельминтов: цестод - 4, трематод - 4, нематод - 5 . 
Гельминты семейства поганковых в Байкальской Сибири

\begin{tabular}{|c|c|c|c|}
\hline Виды гельминтов & Чомга & $\begin{array}{c}\text { Черношейная } \\
\text { поганка } \\
\end{array}$ & $\begin{array}{c}\text { Красношейная } \\
\text { поганка }\end{array}$ \\
\hline \multicolumn{4}{|c|}{ Цестоды } \\
\hline Diphyllobothrium dendriticum (Nitzsch, 1824) & + & & + \\
\hline Ligula intestinalis (Linnaeus, 1758) & + & & \\
\hline Ligula colymbi (Zeder, 1803) & + & & \\
\hline Digramma interrupta (Rudolphi, 1910) & + & & \\
\hline Schistocephalus solidus (Müller, 1776) & + & & \\
\hline Schistocephalus nemachili (Dubinina, 1959) & + & & \\
\hline Tetrabothrius macrocephalus Rudolphi, 1819 & & & + \\
\hline Lateriporus clerci (Johnston, 1912) & + & & + \\
\hline Platyscolex ciliata (Fuhrmann, 1913) & + & & \\
\hline Confluaria furcifera (Krabbe, 1869) & + & & + \\
\hline Confluaria podicipina (Szymanski, 1905) & + & & \\
\hline Diorchis ransomi (Schultz, 1940) & + & & \\
\hline Ichthycotylurus erraticus (Rudolphi, 1809) & & + & \\
\hline Tatria biremis (Kowalewski, 1904) & + & + & \\
\hline Cladotaenia globifera (Batsch, 1786) & + & + & \\
\hline \multicolumn{4}{|c|}{ Трематоды } \\
\hline Plagiorchis laricola Skrjabin, 1924 & + & & \\
\hline Prosthogonimus ovatus (Rudolphi, 1803) & + & + & \\
\hline Prosthogonimus cuneatus (Rudolphi, 1809) & + & & \\
\hline Sphaeridiotrema globulus (Rudolphi, 1819) & + & & \\
\hline Renicola pinguis (Mehlis, 1831) & + & & \\
\hline Echinostoma revolutum (Fröelich, 1802) & + & + & \\
\hline Echinostoma paraulum (Dietz, 1909) & + & & + \\
\hline Echinoparyphium clerci (Skrjabin, 1915) & + & & + \\
\hline Petasiger neocomense (Fuhrmann, 1927) & + & & \\
\hline Petasiger megacanthum (Kotlan, 1922) & + & & + \\
\hline Petasiger skrjabini (Baschkirova, 1941) & + & & \\
\hline Petasiger aeratus (Oschmarin, 1947) & + & & \\
\hline Echinochasmus spinulosus (Rud., 1809) & + & & \\
\hline Echinochasmus coaxatus (Dietz, 1909) & + & & \\
\hline Heterophyes heterophyes (Siebold, 1852) & + & & \\
\hline Notocotylus attenuates (Rudolphi, 1809) & + & & \\
\hline Diplostomum gavium (Guberlet, 1922) & + & + & \\
\hline Tylodelphys clavata (Nordmann, 1832) & + & & \\
\hline $\begin{array}{l}\text { Tylodelphys conifera (Mehlis, 1846; Dubois, } \\
\text { 1937) }\end{array}$ & + & & \\
\hline Apharyngostrigea cornu (Zeder, 1800) & + & & \\
\hline Cotylurus cornutus (Rudolphi, 1808) & + & & \\
\hline Cotylurus erraticus (Rudolphi, 1809) & + & + & + \\
\hline Ophiosoma patagiatum (Creplin, 1846) & + & & \\
\hline Duboisia teganuma (Ishii, 1935) & + & & \\
\hline Bilharziella polonica (Kowalewski, 1895) & + & & \\
\hline
\end{tabular}


Ц. 3. Доржиев, Е. Н. Бадмаева, Ж. Н. Дугаров. Эколого-фаунистический анализ гельминтов водноболотных птиц Байкальской Сибири: 4. Гагаровые, баклановые, цаплевые, поганковые, пастушковые

\begin{tabular}{|c|c|c|c|}
\hline Виды гельминтов & Чомга & $\begin{array}{c}\text { Черношейная } \\
\text { поганка }\end{array}$ & $\begin{array}{c}\text { Красношейная } \\
\text { поганка }\end{array}$ \\
\hline \multicolumn{4}{|c|}{ Нематоды } \\
\hline Epomidiostomum uncinatum (Lundahl, 1848) & + & & \\
\hline Contracaecum spiculigerum (Rudolphi, 1809) & + & & + \\
\hline Tetrameres numenii Mamaev, 1959 & + & + & + \\
\hline Tetrameres skrjabini Panowa, 1926 & + & + & + \\
\hline Echinuria uncinata (Rudolphi, 1819) & + & & + \\
\hline Streptocara crassicauda (Creplin, 1829) & + & & \\
\hline \multicolumn{4}{|c|}{ Скребни } \\
\hline Polymorphus minutus (Goeze, 1782) & + & & + \\
\hline Polymorphus magnus Skrjabin, 1913 & + & & \\
\hline
\end{tabular}

Среди паразитов поганок оказалось большое число специфических видов, не обнаруженных у других групп водно-болотных птиц региона. Так, у всех трех исследованных поганок найден сосальщик Cotylurus erraticus, а у чомги и черношейной поганки - ленточные черви Tatria biremis и Cladotaenia globifera, сосальщик Diplostomum gavium, у чомги и красношейной поганки - Confluaria furcifera [Некрасов, Жатканбаева, 1982; Подковыров и др., 1988; Подковыров, Некрасов, Пыжьянов, 1991]. Лишь у чомги выявлены цестоды Digramma interrupta, Confluaria podicipina, трематоды Renicola pinguis, Tylodelphys clavata, Tylodelphys conifer, Ophiosoma patagiatum Duboisia teganuma, Petasiger neocomense, Petasiger skrjabini, Echinochasmus spinulosus, Echinochasmus coaxatus. Часть этих видов гельминтов, несомненно, обнаружится у других видов поганок при дальнейшем их изучении, поскольку они найдены в других регионах [Быховская-Павловская, 1962; Смогоржевская, 1976; Махмудова, 2013; Яковлева, Лебедева, Иешко, 2013; Кондратова, Иванюшина, Пенкина, 2019; Маралбаева, Ахметов, 2019].

Некоторые виды гельминтов, обнаруженных в поганках, имели еще по одному хозяину из других групп птиц: Petasiger aerates и Apharyngostrigea cornu паразитировали в серой цапле, Tetrabothrius macrocephalus - краснозобой гагаре, Epomidiostomum uncinatum - крякве.

Из приведенного по поганкам материала видно, что эта группа птиц имеет довольно широкий набор гельминтов, среди которых много специфических паразитов.

Семейство пастушковые насчитывает 7 гнездящихся видов в Байкальской Сибири [Доржиев, Бадмаева, 2016]. В нашем распоряжении оказались материалы по гельминтам только лысухи, было вскрыто 28 особей, из них 23 (82,1\%) были зараженными. Выявлено 11 видов паразитов. Цестод зарегистрировано 3 вида Diorchis ransomi (Schultz, 1940), Diorchis sobolevi (Spasskaja, 1950), Diorchis stefanskii Czaplinski, 1956; трематод также 3 - Notocotylus attenuatus (Rudolphi, 1809), Notocotylus gibbus (Mehlis, 1846), Apatemon gracilis (Rudolphi, 1819); нематод один вид - Porrocaecum crassum (Deslongchamps, 1824). Скребней обнаружено 4 вида - Polymorphus minutus (Goeze, 1782), Polymorphus magnus (Skrjabin, 1913), Filicollis anatis [Schrank, 1788], Echinuria uncinata. Круг хозяев всех этих гельминтов обширен, встречались у многих других водоплавающих и околоводных птиц. Только у сосальщика Notocotylus gibbus было всего два хозяина - лысуха и луток [Некрасов, Санжиева, Егоров, 1982]. 
Обнаруженное число видов гельминтов у лысух в Байкальской Сибири составляет малую долю видового состава известных в стране паразитов в данной птице [Быховская-Павловская, 1962; Спасская, 1966; Смогоржевская, 1976; Определитель... 1986; Федорович и др., 2010; Махмудова, 2013; Яковлева, Лебедева, Иешко, 2013; Кондратова, Иванюшина, Пенкина, 2019; Маралбаева, Ахметов, 2019]. Дальнейшие исследования позволят расширить видовой состав гельминтофауны лысухи в регионе.

\section{Заключение}

Из изложенного выше видно, что исследованные водно-болотные птицы заражены широким набором видов гельминтов. Это хорошо заметно на двух видах чомге и лысухе, которые представлены относительно большим количеством особей. В остальных видах наверняка паразитирует большее число видов, но незначительный объем материала не позволил показать общую картину структуры фауны их гельминтов.

Выявлено, что у каждой группы птиц, это хорошо показано на чомге и лысухе, есть специфический видовой набор гельминтов. Основную долю паразитов составляют цестоды и трематоды, нематоды уступают им. Участие акантоцефалов в населении гельминтов исследованных групп птиц низкое. Лишь у лысухи доля скребней по отношению к другим классам гельминтов была несколько выше, но это из-за малого объема вскрытых птиц еще не говорит об истинной картине соотношения представителей разных групп паразитов.

Исследования показали, что многие виды водно-болотных птиц в паразитологическом плане остаются слабо или вообще не изученными. В первую очередь следует обратить внимание на многочисленные и обычные виды, например, серую цаплю, большого баклана, черношейную поганку, лысуху и другие.

\section{Литература}

1. Быховская-Павловская И. Е. Трематоды птиц фауны СССР. Эколого-географический обзор. М.; Л.: Изд-во АН СССР, 1962. 408 с.

2. Доржиев Ц. 3. Птицы Байкальской Сибири: систематический состав, характер пребывания и территориальное размещение // Байкальский зоологический журнал. 2011. № 1(6). С. 30-55.

3. Доржиев Ц. 3., Бадмаева Е. Н. Неворобьиные Non-Passeriformes птицы Республики Бурятия: аннотированный список // Природа Внутренней Азии. Nature of Inner Asia. 2016. № 1(1). C. 7-60.

4. Доржиев Ц. З., Бадмаева Е. Н., Дугаров Ж. Н. Эколого-фаунистический анализ гельминтов водно-болотных птиц Байкальской Сибири: 1. Утиные Anatidae // Природа Внутренней Азии. Nature of Inner Asia. 2019. № 1(10). С. 7-27.

5. Доржиев Ц. 3., Бадмаева Е. Н., Дугаров Ж. Н. Эколого-фаунистический анализ гельминтов водно-болотных птиц Байкальской Сибири: 2. Ржанковые Charadrii // Природа Внутренней Азии. The Nature of Inner Asia. 2019б. № 3 (12). С. 7-32.

6. Доржиев Ц. З., Бадмаева Е. Н., Дугаров Ж. Н. Эколого-фаунистический анализ гельминтов водно-болотных птиц Байкальской Сибири: 3. Чайковые Laridae // Природа Bнутренней Азии. The Nature of Inner Asia. 2020. № 1 (14). С. 66-78.

7. Кондратова К. А., Иванюшина А. М., Пенкина О. Л. Зараженность гельминтами диких водоплавающих птиц северной лесостепной зоны Омской области // Вестник Омского ГАУ. Ветеринария и зоотехния. 2019. № 4 (36). С. 119-125. 
Ц. 3. Доржиев, Е. Н. Бадмаева, Ж. Н. Дугаров. Эколого-фаунистический анализ гельминтов водноболотных птиц Байкальской Сибири: 4. Гагаровые, баклановые, цаплевые, поганковые, пастушковые

8. Маралбаева Д. Г., Ахметов К. К. Особенности распространения трематод семейства Prosthogonimidae (Nicoll, 1924) у птиц на северо-востоке Казахстана // Российский паразитологический журнал. 2019. T. 13, № 3. С. 63-70. DOI: 10.31016/1998-8435-2019-13-3-63-70

9. Махмудова Е.А. Эколого-фаунистический анализ трематод водно-болотных птиц трансграничного озера Джандар в Закавказье // Юг России: экология, развитие. 2013. № 1. С. 67-71.

10. Некрасов А. В. Гельминты диких птиц бассейна озера Байкал. Улан-Удэ: Изд-во БНЦ СО РАН, 2000. 56 c.

11. Некрасов А. В. Паразитологические исследования диких птиц в бассейне озера Байкал // Современные проблемы орнитологии Сибири и Центральной Азии: материалы II Междунар. орнитолог. конф. Улан-Удэ, 2003. Ч. 1. С. 199-200.

12. Некрасов А. В. Скребни некоторых птиц Прибайкалья // Экология и охрана птиц и млекопитающих Забайкалья. Улан-Удэ, 1989. С. 53-60.

13. Некрасов А. В., Жатканбаева Д. Гельминтофауна рыбоядных птиц оз. Байкал // Зоопаразитология Забайкалья. Улан-Удэ, 1982. С. 65-75.

14. Некрасов А. В., Пронин Н. М., Дугаров Ж. Н. Трематоды (Plathelminthes, Trematoda). Гл. 9. Аннотированный список фауны озера Байкал и его водосборного бассейна. Т. 1. Озеро Байкал. Новосибирск: Наука, 2001. Кн. 1. С. 271-305.

15. Некрасов А. В., Санжиева С. Д., Егоров В. Г. Гельминтофауна водоплавающих птиц оз. Байкал // Биологические ресурсы Забайкалья и их охрана. Улан-Удэ, 1982. С. 69-81.

16. Определитель трематод рыбоядных птиц Палеарктики / отв. ред. М. Д. Сонин. M., 1986. 213 c.

17. Ошмарин П. Г. К фауне промысловых животных Бурятии // паразитические черви домашних и диких животных. Владивосток: Изд-во ДВ филиала СО АН СССР, 1965. С. 209-212.

18. Ошмарин П. Г. Описание двух новых видов трематод из печени птиц в связи с анализом их филогенетических отношений // Тр. Горьк. гос. педин-та, 1947. Вып. 12. С. 33-47.

19. Подковыров В. А., Некрасов А. В., Пыжьянов С. В. Большая поганка в Чивыркуйском заливе озера Байкал // Экология и фауна птиц Восточной Сибири. Улан-Удэ: Изд-во БНЦ СО РАН, 1991. С. 140-147.

20. Подковыров В. А., Некрасов А. В., Тимошенко Т. М., Санжиева С. Д. Экологогельминтологическая характеристика поганковых птиц озера Байкал // Проблемы экологии Прибайкалья. Иркутск: Изд-во Иркут. гос. ун-та, 1988. С. 134.

21. Семенова Н. Н., Калмыков А. П., Иванов В. М. Таксономическое разнообразие цестод околоводных птиц дельты Волги и Северного Каспия // Самарская Лука: проблемы региональной и глобальной экологии. 2009. Т. 18, № 4. С. 95-99.

22. Скрябин К. И. Трематоды животных и человека. (Основы трематодологии). М.: Изд-во АН СССР, 1947. Т. І. 515 с.

23. Смогоржевская А. А. Гельминты водоплавающих и болотных птиц фауны Украины. Киев: Наукова думка, 1976, 416 с.

24. Спасская А. А. Гименолепидиды - ленточные гельминты диких и домашних птиц (Основы цестодологии). М.: Изд-во АН СССР, 1963. Т. II, ч. I. 419 с.

25. Спасская А. А. Цестоды птиц СССР. Гименолепидиды. М.: Наука, 1966. 698 с.

26. Тимошенко Т.М. Гельминты рыбоядных птиц дельты р. Селенги // Паразиты и болезни гидробионтов Ледовитоморскойи провинции. Новосибирск: Наука, 1990. С. 117-125.

27. Федорович В. В., Калмыков А. П., Семѐнова Н. Н., Иванов В. М., Кашина Т. Г. Таксономический обзор гельминтов (Cestoda; Nematoda) водоплавающих птиц в дельте Волги // Юг России: экология, развитие. 2010. № 1. С. 134-141. 
28. Шевцов А. А., Заскинд Л. Н. Гельминты и гельминтозы домашних водоплавающих птиц: учеб. пособие. Харьков, 1960. 446 с.

29. Яковлева Г. А., Лебедева Д. И., Иешко Е. П. Трематоды водно-болотных птиц Карелии (по материалам 319-й союзной гельминтологической экспедиции 1958-1962 годов) // Труды Карельского научного центра РАН. 2015. № 2. C. 95-110. DOI: 10/17076/ есо1 119i.

30. Яковлева Г. А., Лебедева Д. И., Иешко Е. П. Эколого-фаунистические особенности видового состава трематод водно-болотных птиц Карелии // Труды Карельского научного центра РАН 2013. № 2. С. 108-110.

\section{ECOLOGICAL AND FAUNISTIC ANALYSIS OF HELMINTHS \\ IN WETLAND BIRDS OF BAIKAL SIBERIA: 4. GAVIIDAE, PHALACROCORACIDAE, ARDEIDAE, PODICIPEDIDAE, RALLIDAE}

Ts. Z. Dorzhiev, E. N. Badmaeva, Zh. N. Dugarov

Tsydypzhap Z. Dorzhiev

Dr. Sci. (Biol.), Prof.,

Dorzhi Banzarov Buryat State University

24a Smolina St., Ulan-Ude 670000, Russia

Institute of General and Experimental Biology SB RAS

6 Sakhyanovoy St., Ulan-Ude 670037, Russia

E-mail: tsydypdor@mail.ru

Evgeniya N. Badmaeva

Cand. Sci. (Biol.), A/Prof.,

Dorzhi Banzarov Buryat State University

24a Smolina St., Ulan-Ude 670000, Russia

E-mail: calidris03@gmail.com

Zhargal N. Dugarov

Cand. Sci. (Biol.),

Institute of General and Experimental Biology SB RAS

6 Sakhyanovoy St., Ulan-Ude 670047, Russia

E-mail: zhar-dug@biol.bscnet.ru

Abstract. The article analyzes the species composition of helminths of 8 bird species from Gaviidae (Gavia stellata, Gavia arctica), Phalacrocoracidae (Phalacrocorax carbo), Ardeidae (Ardea cinerea), Podicipedidae (Podiceps cristatus, Podiceps nigricollis, Podiceps auritus) and Rallidae (Fulica atra) families. The total volume of material is small — 94 birds have been dissected. The sampling is presented predominantly by the great crested grebe and the common coot, the rest of species is represented by 2 to 7 individuals. We have identified 46 types of helminths in the great crested grebe: 13 types of cestodes, 25 types of trematodes, 6 types of nematodes, and 2 types of acanthocephala. 11 types of parasites have been found in the common coot: cestodes - 3, trematodes - 3, nematodes - 1, acanthocephala -4 . Bird parasites are mainly presented by cestodes and trematodes, the share of nematodes is far smaller. The studied groups of birds are infected by acanthocephala less frequently. Only in the common coot the share of acanthocephala in relation to other classes of helminths was 
Ц. 3. Доржиев, Е. Н. Бадмаева, Ж. Н. Дугаров. Эколого-фаунистический анализ гельминтов водноболотных птиц Байкальской Сибири: 4. Гагаровые, баклановые, цаплевые, поганковые, пастушковые

higher. We have established that some of the helminth species are specific for various groups of birds. Many species of waterland birds in parasitological terms remain poorly studied. First of all, we should pay attention to the numerous and common species of birds in Baikal Siberia. Keywords: helminths; bird parasites; Gavia; Phalacrocorax; Podiceps; Ardea; the common coot; Lake Baikal; Baikal Siberia.

Статья поступила в редакцию 27.10.20; одобрена после редактирования 16.12.20; принята к публикации 18.12.20. 